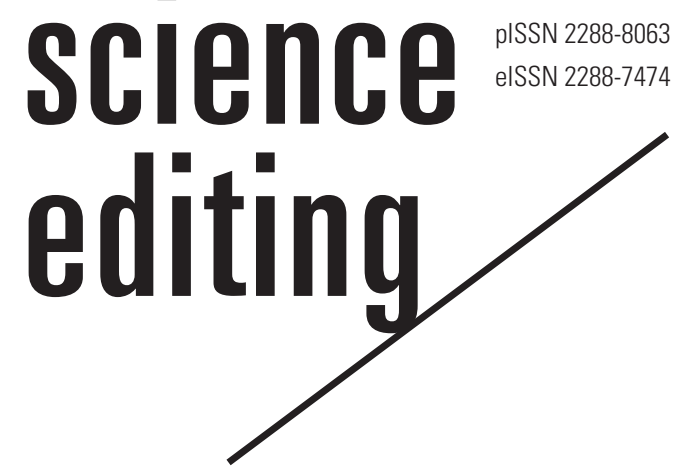

\title{
2018 Intermediate-level training course for manuscript editors
}

\author{
Byung-Ho Yoon \\ Department of Orthopedic Surgery, Inje University Seoul Paik Hospital, Seoul, Korea
}

Date: Once a month, May 17 to August 23, 2018

Venue: National Library of Korea, Seoul, Korea

Theme: 2018 Intermediate-level training course for manuscript editors

Organizer: Korean Council of Science Editors

From May 17 to August 23, 2018, I participated in the 2018 intermediate-level training course for manuscript editors, which was hosted by the Korean Council of Science Editors (KCSE). Afterward, I took and passed the third Korean Manuscript Editors Certification by KCSE. Because I am currently serving as the associate editor of the Journal of Bone Metabolism, I have been interested in the process of manuscript editing.

Due to the increasing importance on research achievements and evaluations, young professors in Korea need to publish more academic papers either willingly or by pressure from their institutions. While the joy of publishing a paper is momentary, the writing process can be a difficult, long-lasting ordeal. Therefore, I wanted to learn how to write papers more efficiently. After I started working as an associate editor for the Journal of Bone Metabolism, I became interested in paper formatting and the composition of academic journals. While managing the academic journal, I found areas for improvement and deficiencies in our journal through submitting my papers to other journals. Having anticipated that this training would help improve the quality of my papers and our academic journal, I participated in the training course for manuscript editors.

The first part of training concerned English grammar for academic writing. I never had a full understanding of English grammar nor found it very interesting before this course. If I had known how necessary English grammar would be during my middle- and high-school years, I would have studied English grammar much more. The middle part of the training involved a lecture about sentence types and structures, such as inconsistent participles. Anyone who has

Received: January 23, 2019 Accepted: January 31, 2019

Correspondence to Byung-Ho Yoon J5045@paik.ac.kr

ORCID

Byung-Ho Yoon

https://orcid.org/0000-0001-8518-6331 peer-reviewed papers would recognize a strange sentence structure but would not be able to explain the reasoning behind it in detail. I learned the rules that determine proper sentence structure and how to correct it, which was really helpful. The last part of the training covered the use of punctuation and rules for academic writing, and I was surprised at the many instructions and meanings. When writing papers, clinicians tend to write sentences that seem meaningful on the surface, as have I. However, I learned about the relevant rules through this 


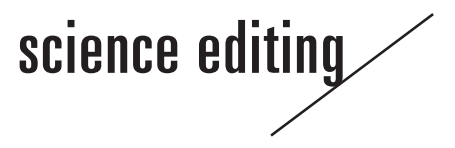

course, and it will help me write better papers. I feel really great that this course has helped me organize my experience accumulated by submitting papers to several academic journals and editing.

When I started taking this course last summer, I was highly motivated. However, over time, whenever I was busy, I struggled, wondering if studying was worth the effort. After the course was over at the end of August, I organized a study group to prepare for an international manuscript editor certificate examination (Board of Editors in the Life Sciences) in December in Korea. During break time, I had instructive conversations with other members, and a bond developed between group members because each of us was doing our best at our position.

Considering that it is important for clinicians to conduct beneficial research and publish the findings in prestigious journals, proofreading and editing papers is critical. This course shared the perspective of those who edit and proofread academic journals and provided a good opportunity for me to master the basics of academic writing. I really appreciate the colleagues who studied with me, and I will not forget the summer of 2018 how my learning and studying has benefitted me.
Many universities and institutions require that professors demonstrate research achievements, so writing academic papers is not optional but mandatory for clinical researchers. In addition, many domestic and international academic journals request manuscripts be submitted in English. However, there is no opportunity to receive education about academic writing or academic journals as part of the medical school curriculum or residency. This course has helped me learn to recognize awkward sentences and understand difficulties that accompany writing English manuscripts. Although I am not able to fully memorize the vast amounts of information I learned in the course, it has allowed me to reflect on the process of writing and reviewing manuscripts during the course, which will help me carry out future research. Lastly, I would like to express my sincere gratitude for KCSE, which continuously offers good curricula.

\section{Conflict of Interest}

No potential conflict of interest relevant to this article was reported. 